\title{
Crop Fertilization Impacts Epidemics and Optimal Latent Period of Biotrophic Fungal Pathogens
}

\author{
Pierre-Antoine Précigout, ${ }^{\dagger}$ David Claessen, and Corinne Robert
}

First and second authors: Institut de Biologie de l'Ecole Normale Supérieure, CNRS-ENS-INSERM UMR8197, Ecole Normale Supérieure, 46 rue d'Ulm, 75005 Paris; and first and third authors: UMR ECOSYS INRA, AgroParisTech, Université Paris-Saclay, 78850 ThivervalGrignon, France.

Accepted for publication 27 April 2017.

\begin{abstract}
Crop pathogens are known to rapidly adapt to agricultural practices. Although cultivar resistance breakdown and resistance to pesticides have been broadly studied, little is known about the adaptation of crop pathogens to fertilization regimes and no epidemiological model has addressed that question. However, this is a critical issue for developing sustainable low-input agriculture. In this article, we use a model of life history evolution of biotrophic wheat fungal pathogens in order to understand how they could adapt to changes in fertilization practices. We focus on a single pathogen life history trait, the latent period, which directly determines the amount of resources allocated to growth and reproduction along with the speed of canopy colonization. We implemented three fertilization scenarios, corresponding to major effects of increased nitrogen fertilization on crops: (i) increase in nutrient concentration in leaves, (ii) increase of leaf

measures to identify putative evolutionary responses of latent period to changes in fertilization level. We observed that annual spore production increases with fertilization, because it results in more resources available to the pathogens. Thus, diminishing the use of fertilizers could reduce biotrophic fungal epidemics. We found a positive relationship between the optimal latent period and fertilization when maximizing total spore production over an entire season. In contrast, we found a negative relationship between the optimal latent period and fertilization when maximizing the within-season exponential growth rate of the pathogen. These contrasting results were consistent over the three tested fertilization scenarios. They suggest that between-strain diversity in the latent period, as has been observed in the field, may be due to diversifying selection in different cultural environments.
\end{abstract} lifespan, and (iii) increase of leaf number (tillering) and size that leads to a bigger canopy size. For every scenario, we used two different fitness
Additional keywords: life history theory, structured-population model.
In contrast to plants or animals whose life history has long been studied (Cohen 1971; 1976; Engen and Saether 1994; Kozłowski 1992), fungi received much less attention in life history theory (Gilchrist et al. 2006), possibly because there is still no consensual fitness measure for these organisms (Pringle and Taylor 2002). However, both multiple crop resistance breakdown (Biffen 1905; Kilpatrick 1975; McDonald and Linde 2002; McIntosh and Brown 1997) and the broad development of pesticide-resistant pathogen strains (Fraaije et al. 2001) have made it very clear that fungal crop pathogens rapidly adapt to cultural practices. Therefore, life history evolution of fungal crop pathogens is a key factor to take into account for designing sustainable agriculture. In this article, we use the ecological framework of life history theory and a consumerresource-based structured-population model to study the response of biotrophic fungal crop leaf pathogens to changes in crop fertilization level.

Most fungal crop pathogens are of real concern because of their propensity to rapidly colonize the crop canopy through successive infection cycles, a phenomenon called polycyclic epidemics. Early in the season, when the canopy is still small, plants are first infected by a primary inoculum. An infection takes place after a spore germinates on the leaf surface. The infection cycle can then be divided into two different steps. First, the mycelium starts growing during a somatic growth period called the latent period, which

${ }^{\dagger}$ Corresponding author: P.-A. Précigout;

E-mail address: pierre-antoine.precigout@cri-paris.org

*The $\boldsymbol{e}$-Xtra logo stands for "electronic extra" and indicates that two appendices are published online.

(c) 2017 The American Phytopathological Society precedes the reproduction period. Then spores are dispersed and deposited on still healthy leaves, often at higher, younger parts of the growing canopy, where they initiate new infections. The infection cycle repeats itself until the end of the growing season (Agrios 2005).

From that picture, one may hypothesize that resources available to the fungus due to fertilization practices modulate the severity of epidemics either at the leaf tissue scale (modifying the infection cycle) or at the canopy scale (modifying the epidemic propagation). Canopies with different densities or architectures may be more or less susceptible to colonization by the pathogen. Several studies have documented the impact of fertilization on cereals and their growth and on plant pathogens (Dordas 2008; Walters and Bingham 2007). Although processes occurring at the leaf scale are rather well studied thanks to several greenhouse experiments, the interplay with canopy-scale processes remains difficult to disentangle. At the leaf scale, the concentration of leaf metabolites and their dynamics vary with fertilization level. It has been shown that fertilization increases the amount of within-leaf nutrients, hence worsening disease severity (Neumann et al. 2004; Olesen et al. 2003b). Several studies have established a correlation between leaf metabolite content and spore production (Kürschner et al. 1992; Robert et al. 2004, 2006). In several cereal species, leaves of plants exposed to low nitrogen levels also undergo natural senescence sooner that those of plants exposed to high nitrogen levels (Jensen and Munk 1997; Robert et al. 2005). Natural leaf senescence can also be accelerated by nutrient uptake by leaf pathogens (Van Den Berg et al. 2007). Shorter leaf lifespan likely means that resources are available to the pathogen for a shorter time period, as modeled by Robert et al. (2008). At the canopy scale, fertilization increases both the number and size of plant organs (leaves and tillers) (Bainbridge 1974; Naseri et al. 2010; Robert et al. 2006) that one can see as a 
global level of resource available to the pathogen. The plant organs are possible infection sites whose abundance, shape, and spacing also influence spore dispersal and microclimate within the crop canopy. Several authors have demonstrated a correlation between canopy architecture and epidemiological development (Calonnec et al. 2013; Lovell et al. 2004; Robert et al. 2008). It remains difficult to determine which plant effect of fertilization (local versus canopy scale) most stimulate epidemic development. Modeling approaches could help in tackling this question because they allow computing scenarios that are impossible or very long and difficult to implement in the field or in the greenhouse. However, to our knowledge, no epidemiological model has addressed the question of either epidemiology or adaptation of crop pathogens to fertilization.

To explore the response of fungal crop pathogens to changes in fertilization levels, we opted for a modeling approach using tools and concepts from ecological life history theory and from consumer-resource theory in periodically forced systems (Grover 1997). There is a limited amount of resources accessible to the fungus within the colonized host tissue. Moreover, the amount of resources decreases over time because of leaf senescence (and associated metabolite remobilization). Under such constraints, life history theory predicts that the pathogen will face an age-atmaturation evolutionary dilemma (Roff 2002). Indeed, it must successfully partition that finite amount of resources between three functions that are key to all organisms: growth, maintenance, and reproduction. Reproduction must be efficient enough to ensure canopy colonization during the polycyclic epidemics but not at the expense of growth and maintenance. Thus, we expect strong resource allocation trade-offs to constrain the evolution of fungi life history traits such as age at maturation, referred to as latent period in fungal pathogens. Latent period is a critical fungal aggressiveness trait in phytopathology research (Lehman and Shaner 1997; Setti et al. 2009; Xue and Hall 1992). Empirical studies have demonstrated the existence of a trade-off between latent period and epidemiological variables such as transmission success (Heraudet et al. 2008) or spore production (Pariaud et al. 2013). The relative latent period of a pathogen strain on different crop cultivars is considered to be a measure of quantitative resistance of the cultivar: the longer the relative latent period, the more resistant the cultivar (Parlevliet 1979; Roumen and de Boef 1993; Shaner and Finney 1980).

To address the question of possible pathogen adaptation to crop fertilization, we used two different possible fitness measures. The first was the annual total spore production. A closely related fitness measure, lifetime reproductive success, has already been proposed for several filamentous fungi (Gilchrist et al. 2006; Pringle and Taylor 2002). We argue that the within-season exponential growth rate of the pathogen may also be a potential fitness measure because there is a seasonal change in plant growth and canopy colonization by the fungus (Garin et al. 2014; Robert et al. 2008). The value of the latent period maximizing either of these quantities is called the optimum latent period. If the pathogen strains currently found in the field were, indeed, adapted to intensive agricultural practices, one could expect them to be near the optimal latent period for high fertilization levels. If the availability of a resource change in the environment, one can expect the resource allocation trade-offs of these pathogens to also change along with the optimal latent period. In this article, we are interested in the effect of crop fertilization on the pathosystem through changes in resource availability for both the consumer (pathogen) and the resource (plant). Using a model of crop and pathogen dynamics, we studied how changing the resource affects the pathogen's sporulation and optimal latent period. The processes involved in linking fertilization to epidemics considered in our model are summarized in Figure 1. We consider changes in optimal latent period in response to changes in fertilization to be an indicative direction of pathogen adaptation to changes in fertilization practices.

In our study, we focused on the consumer-resource aspects of fertilization, ignoring other aspects such as defense mechanisms and microclimate. We implemented three scenarios mimicking three main effects of fertilization on the pathosystem (Fig. 1): (i) within-leaf nutrient concentration, (ii) leaf lifespan, and (iii) canopy size and density (Ferrise et al. 2010; Filella et al. 1995; Hinzman et al. 1986). We simulated these three effects on epidemics and the optimal latent period using the two different fitness measures introduced above.

\section{MATERIALS AND METHODS}

Pathosystem biology. Our model was inspired by biological knowledge of the pathosystem of a wheat crop and a biotrophic fungal pathogen such as leaf rust (Puccinia triticina), although we believe that the model is sufficiently generic to apply to other pathosystems as well; in particular, to other cereal-fungus pathosystems. In this section, we gather some biological knowledge we think useful to the understanding of our model. More details about the pathosystem can be found in Agrios (2005).

Wheat has a semidetermined developmental schedule: 10 to 12 alternate leaves develop on the main axis, the upper-next leaf starting to emerge after the lower one has fully extended. New leaves are created approximately every 100 degree-days (dd) (duration of one phyllochrone) (Lovell et al. 2004). Thus, the age of the leaves approximately reflects their position in the canopy: older leaves near the ground and younger leaves close to the ear. Mature (ligulated) leaves function as source organs for the plant, exporting primary metabolites toward other plant organs. Metabolites are

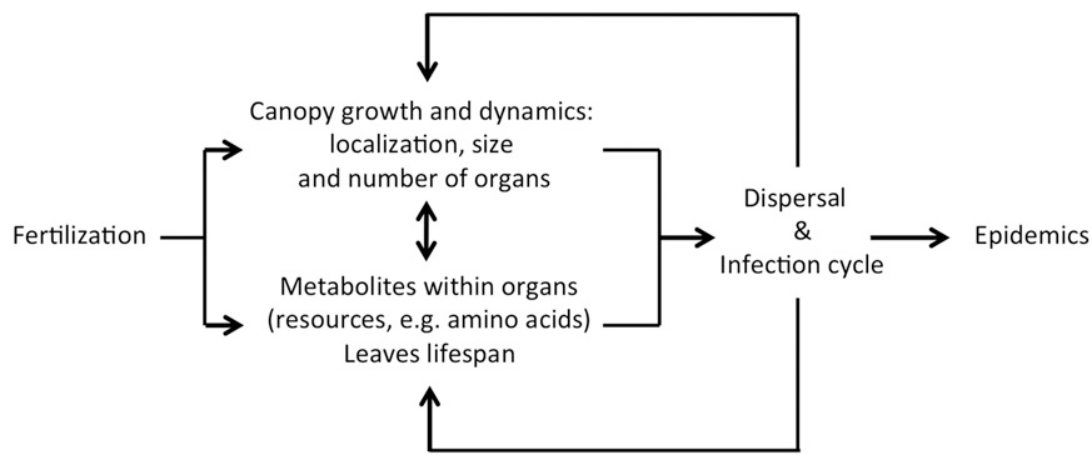

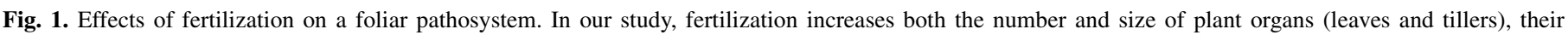

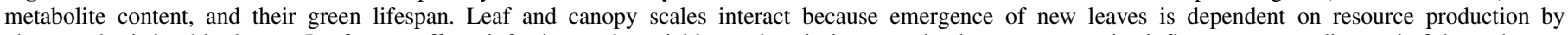

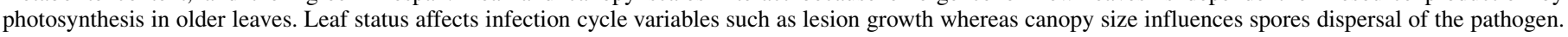

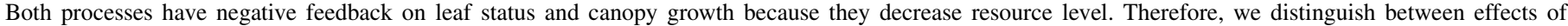
fertilization on the local infection cycle and on the global epidemiological dynamics in our modeling framework. 
also stored in other organs such as roots or stems. The leaf senescence process begins at ligulation of the leaf (the date on which the leaf becomes entirely mature) and lasts until final leaf death (varying from 700 to 1,300 dd in wheat). Concentration of primary metabolites in the leaf decreases over senescence. These metabolites are reallocated to new (upper) leaf creation or to grain filling. Hence, the amount of primary metabolites in a leaf decreases with leaf age, allowing canopy growth by creation of new upper leaves and ear development.

Wheat leaf rust is caused by the biotrophic basidiomycete $P$. triticina Erikss. This fungus reproduces mostly asexually on wheat, urediospores being the most common form of spores produced during polycyclic epidemics. Infection takes place at a local scale on wheat leaves. Lesions on leaves are a few square millimeters in area (Robert et al. 2002). Spores germinate and mycelia start developing, breaking through the epidermis and colonizing living host tissue in all three dimensions (Garnica et al. 2014; Haueisen and Stukenbrock 2016). During that somatic growth phase (latent period), the fungus develops differentiated intracellular hyphae called haustoria, somehow silencing the host immune system and taking up nutrients directly from the plant cell's cytoplasm (Mendgen and Hahn 2002). Once the latent period has been completed, the fungus differentiates asexual reproductive structures named uredia. Uredia are considered mature when they rupture the epidermis, allowing spore dispersion by wind. In standard wheat canopies, urediospores produced on a leaf are able to reach two leaves above and two leaves below them (Frezal et al. 2009). Sporulation goes on during an infectious period up to 3 weeks long for some rust fungi. Spores on leaves impede light reception for photosynthesis. In the fall, urediospore production stops, and a last asexual reproduction cycle leads to the production of rare teliospores able to overwinter. Teliospore germination on wheat residues make the fungus enter a sexual reproduction cycle. Sexual reproduction is associated with overwintering. Sexual basidiospores produced in early spring infect an alternative host, the barberry shrub Berberis vulgaris L., from which asexual aecidiospores will colonize wheat seedlings later in spring. In the northwest of Europe, polycyclic epidemics due to urediospores traditionally start in April or May (1,000 to 1,300 dd after crop sowing, depending on numerous factors such as climate or year) (Duvivier et al. 2016; El Jarroudi et al. 2014). They may start up to 250 dd earlier in the southwest of Europe.

To adequately model the pathosystem and its particularities, we needed to distinguish between the developmental schedule of the plant and that of the pathogen, which are likely to diverge. In other words, we needed a theoretical framework capable of integrating these two developmental scales in the same model over several vegetative seasons.

Model overview. Here, we present the main features of the model that are required to understand how we implemented our main assumptions. The complete model is presented in detail in Appendix 1 .

Our model belongs to the class of physiologically structured population models (de Roos 1997; de Roos and Persson 2013), which are individual-based models that are well suited to formulate model assumptions at the individual scale (here: patch scale) and to integrate the collective dynamics at the population scale (here: canopy scale). We adopted a strategy with two levels of organization: (i) plant physiology and plant-pathogen interactions at the squaremillimeter scale (referred to as the "patch submodel") and (ii) multiannual, seasonally forced patch dynamics and pathogen dispersal at the level of the whole wheat canopy ("canopy-level" model). These two scales of modeling allowed us to represent within- and between-season dynamics of plant-pathogen interactions. To some extent, our model is a structured susceptible-exposed-infected-recovered (SEIR) epidemiological model (Gilchrist et al. 2006; Greenhalgh 1997; Li and Muldowney 1995). In our case, the host population is structured in terms of patch age $(a)$ and patch age of infection $(b)$ as well as in terms of within-tissue resource level, mycelium, and spores biomass.

In our model, we considered that the fungus has a "bang-bang" resource allocation strategy. Its life cycle is split into two distinct phases. First, the latent period is entirely devoted to somatic growth: resources derived from the host are allocated to mycelium biomass production. Second, the infectious period is entirely devoted to reproduction: resources derived from the host are only allocated to spore production. Concerning lesion maturation, we have modeled two assumptions: lesions mature either at (i) a fixed latent period (fixed age) or at (ii) a fixed mycelium size. We found that the overall results do not differ significantly between these rules (Appendix 2). Here, we only present the results with fixed latent period.

Patch submodel. In our model, a patch represents a small portion of photosynthesizing leaf $\left(1 \mathrm{~mm}^{2}\right.$ of leaf surface). The state of a patch is characterized by the variables patch age $(a)$ and resource concentration $(R)$. Infected patches are additionally characterized by the variables age since infection $(b)$, mycelium biomass $(M)$, and spores produced $(S)$. Patch resource renewal is governed by a logistic equation with carrying capacity $(K)$. Renewal is thought to result from photosynthesis whose intensity $[\pi(a)]$ is a decreasing function of age $(a)$ throughout the patch lifespan $(\tau)$. The rate of photosynthesis decreases with age in a wheat leaf because of (i) shading by upper leaves and (ii) apical leaf senescence. In the absence of detailed experimental data on the combined effect of these processes, we have decided to use a linear model as a first approximation, which is the simplest possible model. Note, however, that the actual resource level (R) does not follow this linear decrease because it is limited by the carrying capacity, not photosynthesis, in young patches. Hence, the resource dynamics are insensitive to the precise shape of the photosynthesis function up to the point where photosynthesis becomes a limiting factor.

Resources created in a patch are exported toward other plant organs (global stored resource pool $A$ ) at a rate proportional to patch resource level $(R)$ and coefficient $\psi$.

In an infected patch, the mycelium $(M)$ develops during the somatic growth phase (i.e., the latent period), competing with the plant for resources. Once the latent period has been completed, the mycelium stops growing and the resources acquired by the fungus are allocated to spore production (bang-bang resource allocation strategy). Resource uptake by the fungus follows Michaelis-Menten kinetics, with asymptotic growth rate $I_{\max } M^{2 / 3}$ and half-saturation $R_{H}$, but only a fraction of that energy is converted into either mycelium $(M)$ or spores $(S)$. The rest is lost. The term $\gamma_{M} M$ is the mycelium loss rate and can be interpreted as the sum of mycelium maintenance and decay. All these biological processes stop when the patch resource level drops below a critical level $\left(R_{\text {min }}\right)$ corresponding to patch death. These within-patch processes are described by the following set of ODE:

$$
\frac{d R}{d t}=\pi(a) R\left(1-\frac{R}{K}\right)-\psi R-I_{\max } M^{2 / 3} \frac{R}{R+R_{H}}
$$

with

$$
\pi(a)=\left\{\begin{array}{c}
\pi_{0}\left(1-\frac{a}{\tau}\right) \quad \text { if } a \leq \tau \\
0 \text { otherwise }
\end{array}\right.
$$

During the latent period $(0<b \leq \lambda)$ :

$$
\begin{aligned}
\frac{d M}{d t} & =c_{M} I_{\max } M^{2 / 3} \frac{R}{R+R_{H}}-\gamma_{M} M \\
\frac{d S}{d t} & =0
\end{aligned}
$$

During the infectious period $(b>\lambda)$ : 


$$
\begin{aligned}
& \frac{d M}{d t}=-\gamma_{M} M \\
& \frac{d S}{d t}=c_{S} I_{\max } M^{2 / 3} \frac{R}{R+R_{H}}
\end{aligned}
$$

We assume that the pathogen can only infect healthy patches (no multiple infections). Note that the size of a patch approximates the size of a single lesion. The pathogen acts as a nutrient sink, reducing patch lifespan. Once a patch is infected, it is not contagious until the latent period has been completed. Further, the length of the infectious period depends on the amount of resource left in the patch for spore production; hence, it also depends on the age at which the patch has been infected.

Patches get infected when reached by spores emitted by nearby (age-similar) infectious patches. Spore dispersal decreases with increasing age-distance to sporulating patches. The probability for a patch to become infected is proportional to the sum of the sporulation rates of patches within a range of $\Delta$ degree-days around the patch (maximum dispersal distance) inversely weighted by the age difference between source and target patches. Such a dispersion kernel corresponds to having the maximum chance of dispersing to tissue on the same leaf (same age of leaf in the model) (Frezal et al. 2009).

Canopy-level model. We considered two populations: a single crop and a single biotrophic fungal pathogen strain.

We modeled the wheat crop as a collection of $1-\mathrm{mm}^{2}$ leaf patches. Age is a handy trait with which to structure the population of plant patches: the younger the patch, the higher its position in the canopy and the higher its concentration of primary metabolites. Thus, all patches are characterized by their age $(a)$. This simplification is central to our model. Note that we do not model any intermediate structure such as leaves or plants. Thus, our canopy-level model may be regarded as spatially unidimensional because patch age is inclusive of patch height in the canopy and because there is neither individual plant modeling nor "horizontal" field structure. Healthy patches are characterized by their age $(a)$ only.

Infected (latent or infectious) patches are characterized both by their age (a) (like any other patch) and their age of infection $(b)$. Because patches with different ages have different resource levels, patches infected at two different ages will not offer the pathogen the same amount of resources nor the same time to develop. Thus, both variables $a$ and $b$ are required to fully describe the physiological state of infected patches.

Healthy patches ("susceptible" in terms of SEIR model terminology) colonized by the pathogen become infected but remain noninfectious ("exposed") during the latent period. Then, they become able to infect neighboring patches. Spores produced by infectious patches ("infected") decay at a rate $\gamma_{S}$. The total number of spores produced during a growing season constitutes a spore pool, whose end-of-the-season value is used to calculate both measures of the pathogen's fitness. The spore quantity that remains at the end of each growing season and overwinters determines, if sufficient, the intensity of the next season's epidemics. Dead patches ("recovered") are neither susceptible nor infectious anymore because biotrophic pathogens can only develop on living tissues. With healthy, latent, infectious and dead patches possibly cooccurring in the same patch-age class, our model resembles a structured SEIR epidemiological model.

Pathogen fitness and optimal latent period. Following Gilchrist et al. (2006) and Pringle and Taylor (2002), we considered the total annual production of spores at the epidemic scale to be a potential putative fitness measure for our fungal pathogen. Moreover, in periodically growing populations, the within-season exponential growth rate may be a critical fitness measure ("opportunist strategy," Grover 1997). For foliar fungal pathogens, it has been shown by numerical simulations that a race occurs between plant growth and the colonization of the canopy by the pathogen (Garin et al. 2014; Robert et al. 2008). If the pathogen is not fast enough in the canopy colonization process, the plant may even escape the disease. Thus, we argue that the within-season exponential growth rate of the pathogen may represent another potential fitness measure in our system. In the following, we assign the term "optimal latent period" to the value of the latent period parameter maximizing either of these two quantities.

The total annual production of spores at the epidemic scale $\left[P\left(T_{\text {end }}\right)\right]$ is measured at the end of the last year of a 10-year simulation (10 years is long enough for the system to reach a stationary year-to-year dynamics).

The within-season exponential growth rate of the pathogen is computed as follows:

$$
r=\frac{L T R}{\lambda}
$$

where $L T R=c_{L T R} S\left(a_{\infty}\right) ; \lambda=$ the latent period serving as a minimum generation time; $S\left(a_{\infty}\right)=$ the patch-level, average lifetime spore biomass production; and $c_{L T R}=$ the number of patches infected by one unit of spore biomass. The quantity LTR can be regarded as the patch-level lifetime reproductive success.

Fertilization scenarios. To model the effect of nitrogen fertilization on crop resources and physiology, we implemented three scenarios mimicking three main effects of fertilization on the crop (Fig. 1): (i) within-leaf metabolite concentration, (ii) leaf lifespan, and (iii) canopy size. In the first two scenarios, we changed the resource level at the leaf scale.

In the metabolite concentration (MC) scenario, we changed within-patch resource levels by artificially increasing or decreasing the patch carrying capacity $(K)$ (equation 1$)$ (e.g., the maximum amount of resources in the patch). This scenario mimics the increased concentration of primary metabolites in leaves of more highly fertilized crops.

In the leaf lifespan (LL) scenario, we artificially changed patch lifespan by varying the parameter $\tau$ (equation 2 ): the longer the patch lives, the more resources it produces by photosynthesis. This scenario mimics the increased leaf lifespan in leaves of more highly fertilized crops.

Contrary to the two previous scenarios, the third, the leaf area index (LAI) scenario, modifies the resource level at the canopy scale by changing the maximum patch creation rate $(\rho)$. This scenario mimics the increase in leaf surfaces and tiller numbers in highly fertilized crops, which results in increased LAI.

Analysis methods and simulations. We studied the model dynamics using numerical simulations. The patch submodel was implemented in Matlab for numerical integration of the ordinary differential equations (ODEs) for $R, M$, and $S$ (equations 1 to 4 ). The canopy-level model was implemented using the Escalator Boxcar Train method (de Roos 1997) and the EBTtool software package (de Roos 2014). This method discretizes the continuous patch distributions into cohorts of patches of similar patch ages $(a)$ and similar infection ages $(b)$. Each cohort is characterized by the total number of patches in the corresponding age interval and the cohort's average patch-level state variables $(a, b, R, M$, and $S)$ of the patches. The dynamics of each cohort are described by the ODEs that describe the dynamics of its patch-level state variables and the number of patches in each cohort. In our simulations, new cohorts are created every 10 time units, where the time unit is $1 \mathrm{dd}$. The number of cohorts increases during the growing season via the creation of newborn healthy cohorts (cohorts with $a=0$ ) and via the creation of newly infected cohorts (cohorts with $b=0$ ). The total number of cohorts typically reaches in the hundreds without pathogen or in the thousands with pathogen.

To study the impact of fertilization on epidemics and on optimal latent period, we carried out sensitivity analysis for each of the three resource parameters $K, \rho$, and $\tau$. Results of Figures 2 and 3 are from the Matlab implementation of the patch submodel. Results of 
Figures 4, 5, 6, and 7 are from the EBTtool implementation of the canopy-level model. In Figure 4, the amount of $R$ produced over an epidemic is calculated by integrating the photosynthesis term in equation 1 for every patch between infection start $T_{\text {inoc }}$ and the end of the growing season $\left(T_{\text {season }}\right)$. In Figure 7 , optimal latent period can only be a multiple of 10 because of the time scale of new cohort creation (see above). Regressions have been added to these data to emphasize the relationship between fertilization parameters and optimal latent periods.

\section{RESULTS}

Effect of resource level at the patch scale. The effect of an increase in fertilization parameters $K$ (patch resource carrying capacity) and $\tau$ (patch lifespan) on resource allocation in a single infected patch for different latent periods $\lambda$ is shown in Figure 2.

For every combination of these parameters, the longer the latent period, the more the pathogen depletes the patch resource and, therefore, the sooner the patch dies (Fig. 2, difference between green solid and black dotted curve increases). Mycelium biomass always increases with latent period.

Increasing $K$ increases the amount of resource within the patch (Fig. 2, compare upper and middle panels). For each latent period value, increasing $K$ increases the amount of mycelium and spores produced. Maximum spore production occurs at the intermediate latent period.

Increasing $\tau$ leads to longer-lasting patches, with no increase in the patch maximum resource concentration (Fig. 2, compare middle and bottom three panels, $K=2$ and $\tau=750$ or $1,000 \mathrm{dd}$ ). There is no visible difference in mycelium biomass production but spore production is higher than in the previous simulations. For the last parameter combination, spore production is maximum at a long latent period, showing that the optimal latent period is longer than in previous simulations.

The effect of the latent period on the spore production at the patch level for two values of $\tau$ and $K$ and for a single age at infection (200 dd) is shown in Figure 3. Spore production increases with both $\tau$ and $K$. Spore production also strongly depends on the latent period, with an optimal period that varies with resource conditions: the more resources, the longer the optimal latency. For very long latent periods, the spore production decreases to zero.

Effect of fertilization at the canopy level. The impact of fertilization parameters $K, \tau$, and $\rho$ on canopy size, primary production, and resource allocation at the wheat canopy scale is shown in Figure 4. Canopy size increases linearly with $\rho$ whereas it has a sigmoid response to a change in $K$ and $\tau$ (Fig. 4A, B, and C). In the former case (Fig. 4B), canopy size is less sensitive to an increase of patch lifespan $(\tau)$ for biologically realistic parameter values $(600$ to $1,000 \mathrm{dd}$ ).

The three scenarios of nitrogen fertilization used in our work are not independently simulated in our model because of canopy functioning feedbacks. In scenario MC, we increased patch resource carrying capacity but also canopy size indirectly via leaf resource exportation and resource allocation to patch creation. More resources in patches means more resources exported toward plant nutrient sinks $(A)$ and then more resources available for canopy growth. Canopy growth in this scenario remained less sensitive to fertilization than in the LAI scenario (compare Fig. 4A and C). Similarly, patch lifespan in scenario MC slightly increased with $K$; a healthy patch lived approximately $500 \mathrm{dd}$ at $K=0.1$ and approximately $800 \mathrm{dd}$ at $K=2$ (theoretical value $=750 \mathrm{dd}$ ) (data not shown). In scenario LAI, maximum patch creation rate was the only
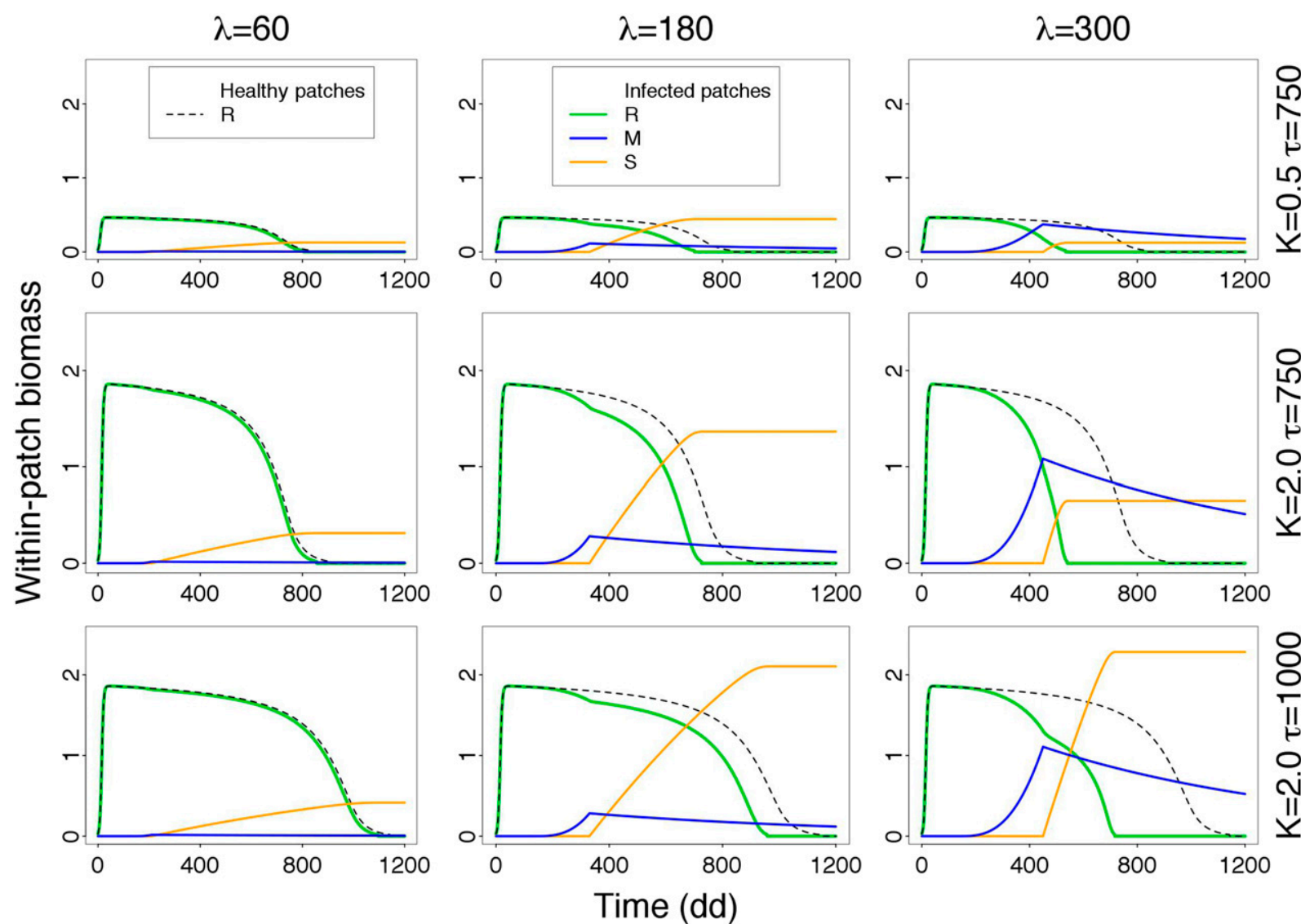

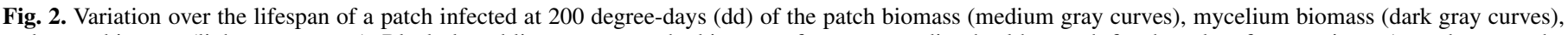

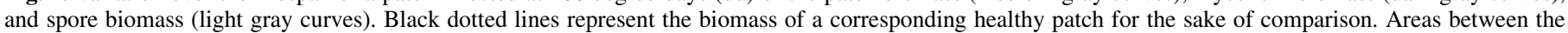

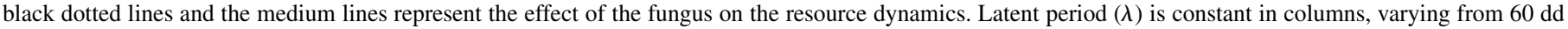
(left) to $180 \mathrm{dd}$ (middle) and $300 \mathrm{dd}$ (right). Upper row, $K=0.5, \tau=750 \mathrm{dd}$. Middle row, $K=2, \tau=750 \mathrm{dd}$. Bottom row, $K=2, \tau=1,000 \mathrm{dd}$. 
parameter to change, with no feedback on patch lifespan (constant at $750 \mathrm{dd}$ for all values of $\rho$ tested) (data not shown). Patch maximum resource concentration did not change in the LAI scenario either.
Total resource produced (primary production) during a growing season increased linearly with fertilization level (Fig. 4D, E, and F). Annual primary production was quantitatively similar in all three scenarios, though a bit less in the LL scenario. Total primary

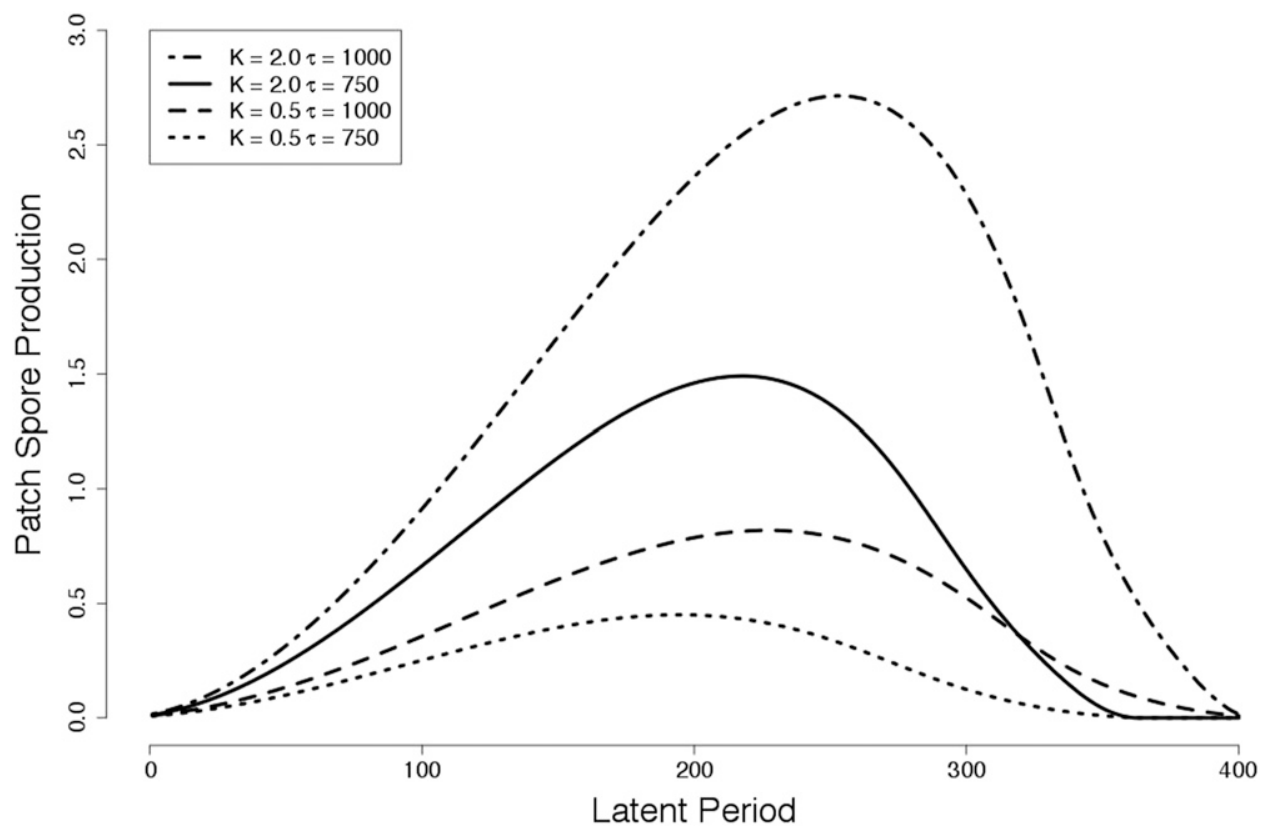

Fig. 3. Spore production of a patch infected at 200 degree-days (dd) for a range of latent periods. Dotted line, $K=0.5, \tau=750 \mathrm{dd}$; solid line, $K=2, \tau=750 \mathrm{dd}$; and mixed line, $K=2, \tau=1,000 \mathrm{dd}$. A fourth parameter combination has been added for the sake of comparison: dashed line, $K=0.5, \tau=1,000 \mathrm{dd}$. Maximum values of these curves are the optimal latent periods (for spore production) at the patch level and reflect a trade-off in resource allocation between mycelium growth and spore production. Typically, a latent period shorter than optimal results in a too-low sporulation rate due to small mycelium size, whereas a latent period longer than optimal suffers from too little resources left for spore production.
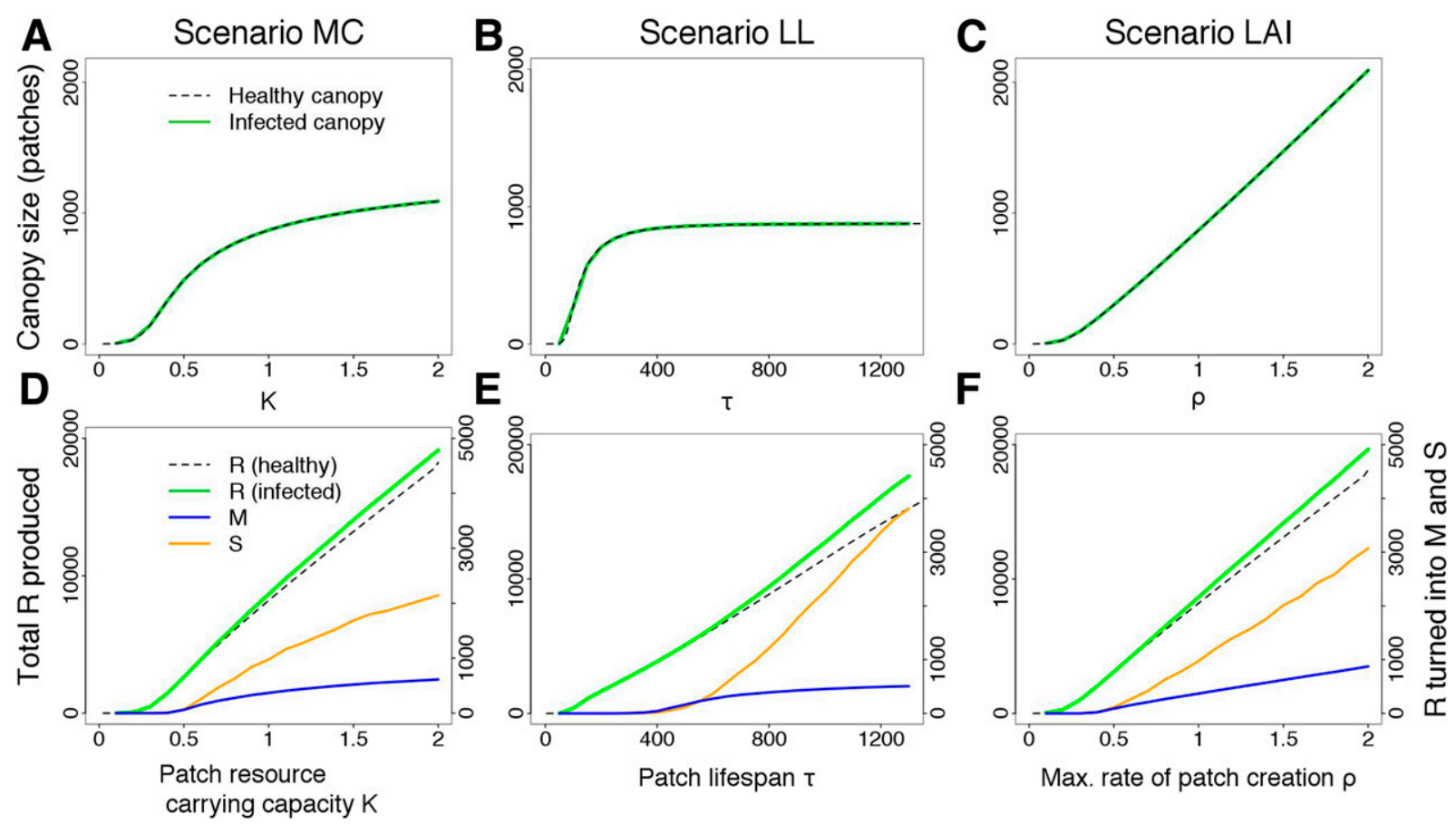

Fig. 4. A, B, and C, Relation between canopy size (number of patches) and fertilization level for each of our three fertilization scenarios. $K=$ patch resource carrying capacity (metabolite concentration [MC] scenario), $\tau=$ patch lifespan (leaf lifespan [LL] scenario), and $\rho=$ maximum patch creation rate (leaf area index [LAI] scenario). Black dotted lines refer to canopies without pathogens and solid lines refer to infected canopies. D, E, and $\mathbf{F}$, Relation between resources $(R)$ produced by an infected canopy over an epidemic (medium gray) and total resource transformed into mycelium ( $M$, dark gray) or spores $(S$, light gray) to variable fertilization level for fertilization scenarios MC, LL, and LAI, respectively. Medium gray curves = patch biomass, dark gray curves = mycelium biomass, and light gray curves $=$ spore biomass. Black dotted lines represent the amount of $R$ produced by a healthy canopy over the same time for the sake of comparison. 
production was slightly higher in infected canopies than in healthy canopies, up to 2,5 , and $9 \%$ in scenarios MC, LAI, and LL respectively. Nevertheless, the amount of resource exported by the plant for its own functioning (export toward $A$ ) was 10 to $30 \%$ less in infected canopies than in healthy canopies (data not shown).

Both spore and mycelium biomass production increased with $K$, $\rho$, and $\tau$. Spore biomass increased faster than mycelium biomass. The proportion of total produced biomass of mycelium was, at most, $3 \%$ in the LL scenario and $4 \%$ in the MC and LAI scenarios. The proportion of total produced biomass of spores was, at most, $15 \%$ in the MC and LAI scenarios and $25 \%$ in the LL scenario.

In all tested scenarios, more resources were usually allocated to spores than to mycelium production. Increasing each of the fertilization parameters ended up favoring spore production over mycelium production.

The impact of a change in each fertilization parameter on the temporal dynamics of the infected canopy is shown in Figure 5. Two-year time series of the asymptotic dynamics allowed comparison of the proportion of healthy, latent, and infected patches over time.

In all four panels of Figure 5, patches are healthy (green lines) until 1,000 dd after the start of the growing season, the date at which the canopy is first inoculated. The increase of healthy patches is followed by an increase of latent patches as they become infected (blue lines), those same patches becoming infectious a latent period later (orange lines). Patches finally die, whether they have been infected or not (dotted lines).

Canopy size did not change when doubling the patch resource carrying capacity $K$ (Fig. 5A and B), slightly increased when increasing patch lifespan $(\tau)$ from 750 to $1,000 \mathrm{dd}$ (Fig. 5A and C), and more than doubled when doubling the maximum patch creation rate $(\rho)$ (Fig. 5A and D).

Increasing any of the fertilization parameters $K, \rho$, and $\tau$ led to an increase in the number of latent and sporulating patches, although with different consequences. Doubling $K$ increased the proportion of infected patches (more than $90 \%$ of patches became infected) (Fig. 5B) whereas it did not when doubling $\rho$ or increasing $\tau$ (less than $80 \%$ of patches became infected) (Fig. 5A, C, and D). Epidemic development was faster when increasing $K$ compared with $\tau$ or $\rho$. In these latter cases, more patches died at the latent state and the maximum number of infected patches (both latent and sporulating) was reached earlier and leveled off, whereas it did not when increasing $K$ (compare Fig. 5B to C and D).

Effect of fertilization on optimal latent period. The impact of fertilization on the optimal latent period is shown in Figures 6 and 7. For the three fertilization scenarios, at every latent period, increasing fertilization increased spore production (Fig. 6A, $\mathrm{C}$, and $\mathrm{E})$ and within-season exponential growth rate of the pathogen (Fig. 6B, D, and F). Epidemics are not sustainable if $K<$ 0.5 and if $\rho<0.4$ because spore production is not sufficient for enough spores to overwinter and create enough infection the next growing season (Fig. 7, dashed areas). This phenomenon does not occur in the LL scenario (Fig. 7, middle panel). At a given resource level, epidemics cannot take place if the latent period is too short or too long. If the latent period is too short, mycelium concentration remains very low and, hence, the spore production rate is too low for epidemics to be perennial. If the latent period is too long, all resources taken up by the pathogen are allocated in mycelium growth and the resource pool is depleted when it turns to sporulation. As a result of this resource allocation trade-off, the value of the latent period maximizing either the annual spore production $\left[P\left(T_{\text {end }}\right)\right]$ or the within-season exponential growth rate of the pathogen $(r)$ is intermediate between these two extreme cases.

The optimal latent period maximizing spore production increased with the fertilization parameters (Fig. 7, filled circles). It varied from 110 to $150 \mathrm{dd}$ as $K$ or $\rho$ increased from 0.5 to 2 . The optimal latent period was most sensitive to $\tau$ over the range of values tested, more than doubling between $\tau=400(\lambda=80)$ and $\tau=1,300(\lambda=200)$. The optimal latent period maximizing withinseason exponential growth rate of the pathogen always decreased with the fertilization parameters (Fig. 7, empty diamonds). It was divided by two over the range of parameter values tested (from approximately $100 \mathrm{dd}$ at $K=0.5, \rho=0.4$, and $\tau=400$ to approximately $50 \mathrm{dd}$ at $K=2, \rho=2$, and $\tau=1300$ ). The difference between the latent periods calculated with either fitness measures increased with the fertilization parameters. Both fitness measures gave similar optimal latent periods at low resource levels ( $K=0.5$, $\rho<0.6$, and $<500)$.
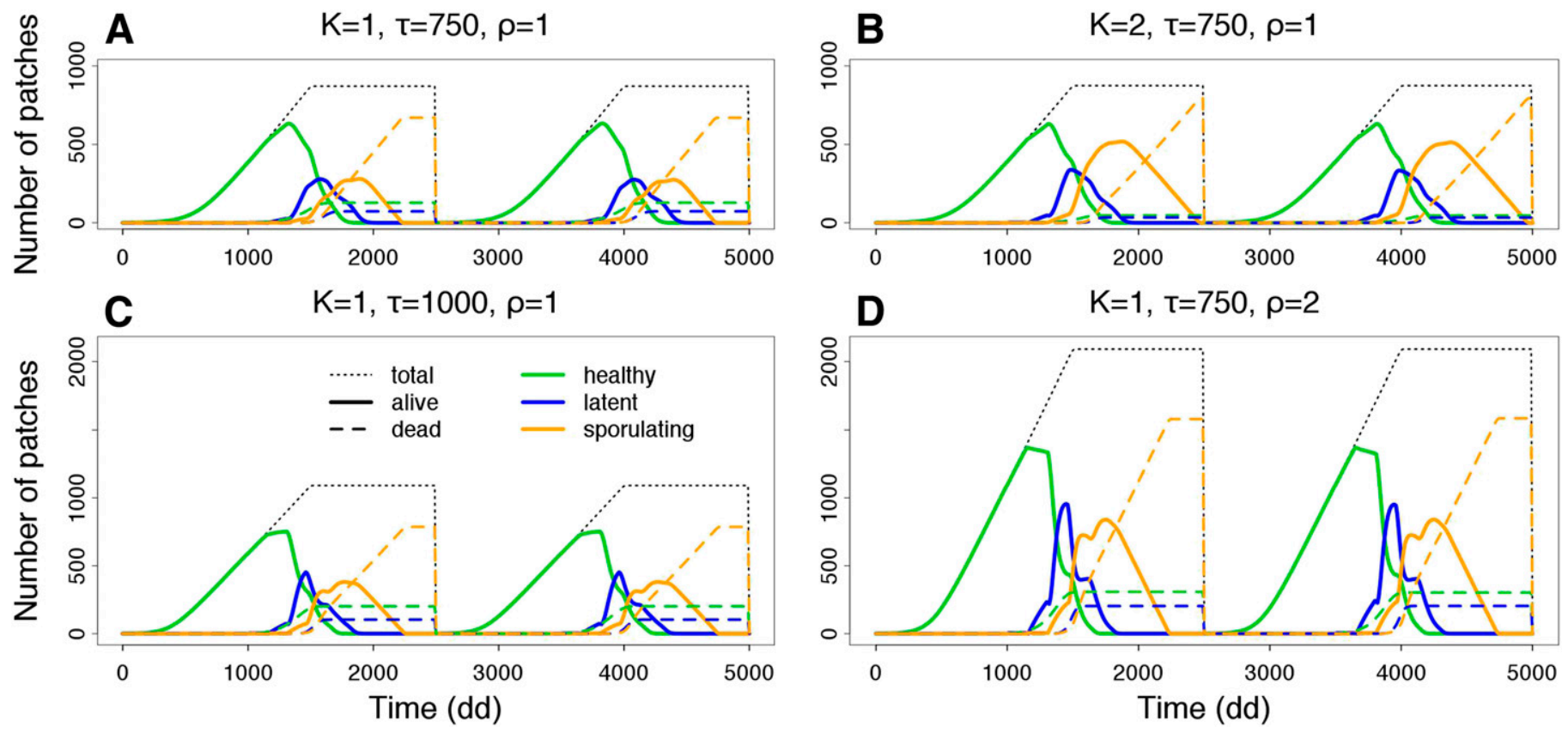

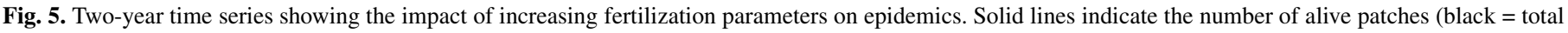

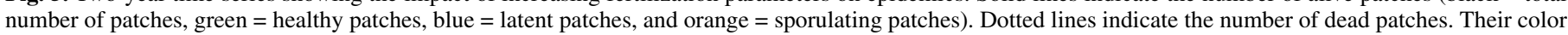

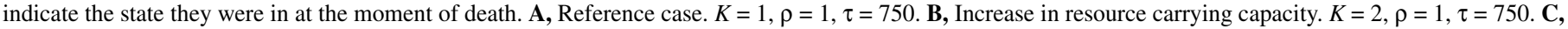
Increase in patch lifespan. $K=1, \rho=1, \tau=1,000$. D, Increase in maximum patch creation rate. $K=1, \rho=2, \tau=750$. 


\section{DISCUSSION}

Nitrogen fertilization is known to change crop physiology and architecture in three major ways by changing the amount or dynamics of (i) within-leaf metabolites, (ii) leaf lifespan, and (iii) number and size of leaves and tillers, hence modifying canopy size and architecture (Ferrise et al. 2010; Filella et al. 1995; Hinzman et al. 1986; Walters and Bingham 2007). We designed three scenarios to study these three effects in our model. Each of these changes influenced the quantity of host resources available to leaf pathogens. In our study, an increase in fertilization led to an increase of resource quantity available for crop pathogens. We found that spore production and severity of epidemics were predicted to increase with fertilization for the three tested scenarios. This is consistent with many experimental studies (Daamen et al. 1989; Jensen and Munk 1997; Kürschner et al. 1992; Lovell et al. 1997; Neumann et al. 2004; Olesen et al. 2003a; Robert et al. 2002, 2004; Walters and Bingham 2007).

We used two different fitness measures to identify the pathogen optimal latent period under different fertilization levels. When pathogen fitness was defined as the annual spore production, we found a positive relationship between optimal latent period and fertilization. In contrast, when pathogen fitness was defined as the within-season exponential growth rate of the pathogen, we found a negative relationship between optimal latent period and fertilization. Thus, depending on which fitness measure is best suited for the considered pathosystem and its environment, one can make different hypotheses regarding the consequences of reducing fertilization. Our study shows that a change in fertilization practices may change pathogen life history, possibly altering the aggressiveness profiles of the different pathogen species and strains.

Effect of fertilization on optimal latent period and consequences. One main result of our theoretical study was the establishment of a relationship between a pathogen's optimal latent period and fertilization. The optimal latent period is the latent period that maximizes pathogen fitness. Therefore, it indicates a putative direction of evolution of the latent period if the fertilization changes over the years. We used two different fitness measures to predict the optimal latent period. We defined the optimal latent period as the value of the latent period maximizing either annual spore production at the epidemic scale (fitness defined as spore production over an entire season) or canopy colonization through several infection cycles (fitness defined as within-season exponential growth rate).

We argue that annual spore production could be an appropriate fitness measure in systems where the initial colonization of new fields (the next season) and overwintering are more limiting factors than within-season, between-strain competition. We found that this fitness measure tends to favor long latent periods (Fig. 7) that have a high sporulation rate. Under low fertilization, we predict that strains with shorter latent periods will be positively selected, resulting in pathogens with shorter infection cycles. In terms of plant-pathogen interactions, the number of leaves that emerge per latent period (the so-called pathochron of Lovell et al. 2004) would decrease, leading to pathogens spreading upward more rapidly in the canopy but producing fewer spores. In contrast, the within-season exponential growth rate could be an appropriate fitness measure in systems where between-strain competition is a more limiting factor
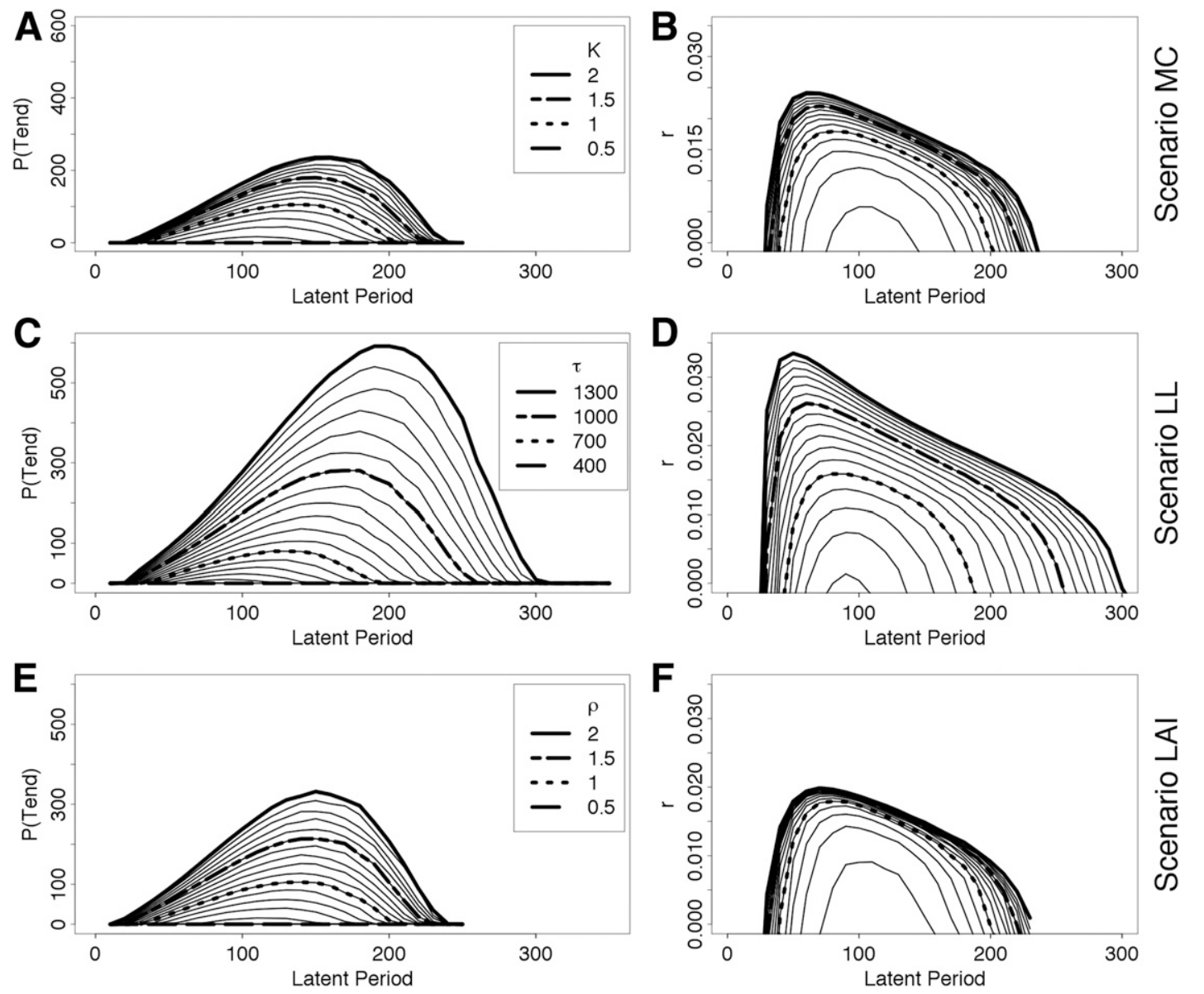

Fig. 6. Fitness curves for range of fertilization and for two different fitness definitions. The summit of each curve indicates the optimal latent period. A, C, and $\mathbf{E}$, Variation of total seasonal spore production $[P(T e n d)]$ with pathogen's latent period. $\mathbf{B}, \mathbf{D}$, and $\mathbf{F}$, Variation of within-season exponential growth rate of the pathogen $r$ with latent period (see equation 5 in the text for $r$ calculation). $K=$ patch resource carrying capacity, $\rho=$ maximum patch creation rate, and $\tau=$ patch lifespan. 
than initial colonization. We found that this fitness measure tends to favor short latent periods (Fig. 7) that have a short generation time and, hence, spread rapidly though the canopy. Under low fertilization, we predict that strains with a longer latent period will be positively selected.

It is interesting to note that, at high fertilization, the two predicted optimal latent periods for either fitness measure strongly differed, suggesting that there is room for multiple pathogen strains with different life history strategies. In such environments, the existence
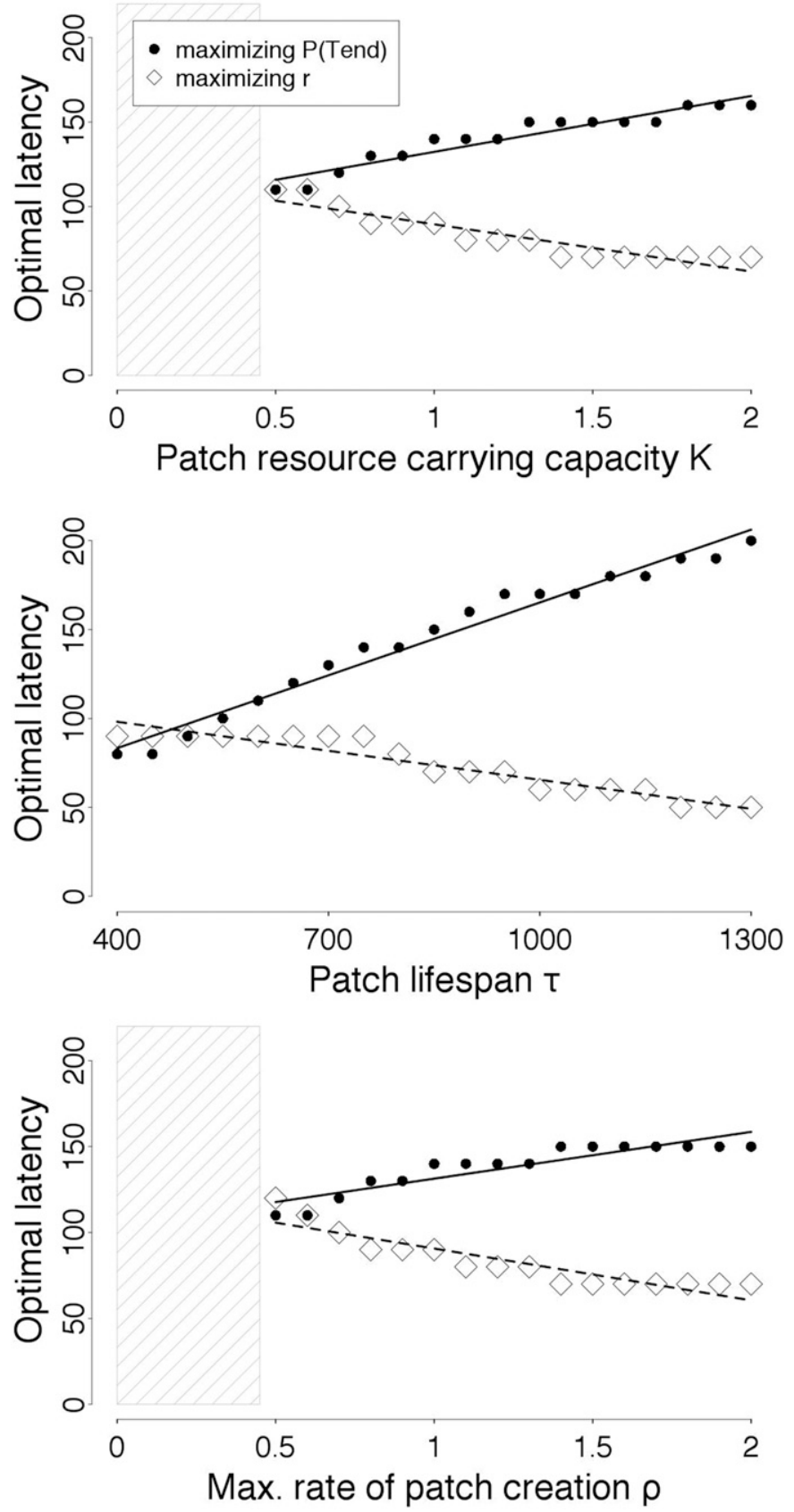

Fig. 7. Variation of optimal latent periods with fertilization in the metabolite concentration (MC, upper panel), leaf lifespan (LL, middle panel), and leaf area index (LAI, lower panel) fertilization scenarios. Full circles and solid lines are optimal latent periods corresponding to seasonal spore production as a fitness measure. Open diamonds and dotted lines are optimal latent periods corresponding to within-season exponential growth rate as a fitness measure of the pathogen. Dots and diamonds correspond to maximum values of curves in Figure 6. Lines are linear regressions added for the sake of clarity. There are no sustainable epidemics in the striped areas of the parameter space. $K=$ patch resource carrying capacity, $\rho=$ maximum patch creation rate, and $\tau=$ patch lifespan. of distinct local maxima in the fitness landscape could indicate that fast-colonizing strains (with a short latent period) and more reproductive strains (longer latent period) may be able to cooccur. Indeed, pathogen subpopulations of Erysiphe necator and Zymoseptoria tritici with distinct latent periods have been identified in the field by Montarry et al. (2008) and Suffert et al. (2015), respectively. In contrast, at low fertilization, both fitness measures lead to similar predictions of the optimal latent period (Fig. 7). This suggests that reducing crop fertilization may result in a greater homogeneity of pathogen populations in the field. This result is consistent with classical foodweb theory, predicting a positive relationship between diversity and primary productivity (Loreau 1998; Tilman et al. 2001).

Data and optimal latent period. The data available in the literature show contrasting results in the relationship between latent period and fertilization treatment. On the one hand, Lecompte et al. (2010) showed that high nitrate nutrition of tomato increased the latent period of the necrotrophic pathogen Botrytis cinerea. Similar results were obtained by Abro et al. (2013) for two strains of the same pathogen, alone or together with biocontrol agents. On the other hand, Jensen (1995) showed that a reduction in nitrogen treatment on barley prolonged the latent period of biotrophic E. graminis. These latter results are in the line of Bainbridge (1974), arguing that, with more nitrogen, the generation interval of E. graminis was smaller. Lovell et al. (1997) observed a lag in the progression of $Z$. tritici incidence in low-nitrogen conditions and suggested that the latent period should be shorter in high-nitrogen crops. These differences may reflect antagonistic host exploitation strategies of biotrophic and hemibiotrophic versus necrotrophic fungi. However, these experiments show the physiological response of a fungal strain to different levels of fertilization but do not teach us anything about the optimal latent period. They cannot be used to test our results on the impact of fertilization on potential fungal adaptation.

Our predictions on the optimal latent period could be compared with observations of latent periods of pathogens that, for long periods, have infected crops cultivated under different levels of fertilization. In such cases, fungal populations could tend to be close to their evolutionary optimum for the local fertilization level. One could compare the distribution and the peaks of measured latent periods in these different fertilization conditions to estimate an empirical measure of the optimal latent period. Estimating experimentally the optimal latent period is rather difficult. We are not aware of such studies either in the field or in the greenhouse. Protocols in controlled conditions could be used to test whether pathogens adapt to the resource level of their environment, by comparing latent period and spore production of in vitro cultures of pathogen strains grown for many generations on agar complemented media at different resource levels or, even better, on plants grown with varied fertilization levels. Such protocols have been used by Alexander et al. (1985) and Lehman and Shaner (1997) to study adaptation of biotrophic pathogens Uromyces appendiculatus and $P$. recondita f. sp. tritici to partially resistant bean and wheat cultivars, respectively. Field measurements of latent periods and spore production in crops that have experienced different fertilization levels would also prove very interesting (but possibly confounded by interactions with other environmental factors such as climate, initial inoculum, and cultivars). From this perspective, it is interesting to note that fertilization practices changed a lot in western Europe after World War II but that change has been more recent in eastern Europe, where cereal culture still remains quite unchanged in some places. Measuring latent period and spore production for several varieties during several years in these different environments could allow us to test the hypothesis of evolving infection cycles under different fertilizations.

Our model predicts a fairly strong effect of the leaf lifespan on pathogen development and on the optimal latent period. This has previously been predicted in the wheat three-dimensional modeling work done by Robert et al. (2008). Unfortunately, there are only a 
few experimental data on this aspect. However, few empirical studies have shown a negative effect of leaf age on pathogen lesion development (Farber and Mundt 2017). Our work suggests that the effect of leaf age could be explained by earlier senescence. Furthermore, Suffert et al. (2015) have shown that the latent period of the fungal population increases from winter to spring conditions. They propose that this variation is driven by seasonal fluctuations in environmental conditions. Our study suggests an alternative additional explanation: crop physiology. We hypothesize that this type of variation could affect which pathogen strain dominates in which part of the year. The competition between multiple pathogen strains is the subject of ongoing modeling work (unpublished data).

Spore production under varied fertilization levels. In our model, we show that annual spore production increases with foliar resource concentration, leaf lifespan, and canopy size (Fig. 4). Over the explored area of the parameter space, spore production was most sensitive to canopy size and leaf lifespan. Several empirical data on spore production are consistent with our prediction of an increased spore production under a higher fertilization level. At the leaf scale, Robert et al. (2004, 2006) established a positive correlation between leaf nitrogen content and spore production by $P$. tritici. Increase of spore production with canopy size has also been observed (Daamen et al. 1989; Jensen and Munk 1997; Smith and Blair 1950). It was sometimes hypothesized that this increase could be linked to a favorable microclimate. Our results show that increasing canopy size and the associated level of resource for the pathogen could play a role to explain this effect. From an epidemiological point of view, bigger canopies represent a higher concentration of putative infection sites. In classic SEIR models, there is always a minimum number of putative infection sites necessary for epidemic development (Heesterbeek 2002). We observed the same effect in our simulations under very low fertilization, where no epidemic could develop due to insufficient canopy size (Figs. 4D and F and 7, dashed area). We found a strong effect of patch lifespan on spore production. Until now, this has not been studied experimentally. However, in recent modeling studies, leaf lifespan has been identified as a sensitive host parameter for determining disease severity of Z. tritici (Garin et al. 2014; Robert et al. 2008).

Of the three different effects of fertilization we have considered, two were at the foliar scale (changing metabolites and senescence) and one at the canopy scale. Different crops do not respond the same way to fertilization: wheat, barley, and rice respond to fertilization first through their canopy size, whereas maize responds mainly by within-leaf nitrogen content (Robert et al. 2004; Savary et al. 1995). Therefore, the theoretical framework we have developed should allow comparison of strategies of different species.

Modeling choices and hypothesis. A major assumption in our model is that fertilization affects pathogen development by increasing the level of resources available to the pathogen by increasing both the canopy size and the within-leaf nutrient concentration. By doing so, we did not consider other possible processes that could be influenced by fertilization such as plant immunity and changes in microclimate due to variation in crop architecture (Walters and Bingham 2007). By changing canopy architecture, fertilization may affect spore dispersal (Garin et al. 2014; Gigot et al. 2014; Robert et al. 2008; Saint-Jean et al. 2004). Increasing leaf density can influence spore dispersal around a sporulating lesion. Bigger and more numerous leaves decrease the distance between leaves, thus possibly favoring local dispersal of the fungus (Garin et al. 2014). However, withincanopy long-distance dispersal could be reduced in denser canopies. These entangled antagonistic processes can be approximated in our model by making the dispersal parameter $\Delta$ (Table 1$)$ dependent on the canopy density. Moreover, canopy architecture also influences microclimate that could affect lesion (Bernard et al. 2013) and disease development (Aust and Hoyningen-Huene 1986; English et al. 1989; Lemmens et al. 2004). For example, denser rice canopies are moister and likely more favorable to sporulation of the hemibiotrophic rice blast agent Pyricularia oryzae (Kürschner et al. 1992). Here again, this might be included in the model by an effect on the infection strength (Table $1, \theta_{\max }$ ).

Because many plant defense compounds contain nitrogen, especially antifungal protein effectors, one would expect a positive correlation between nitrogen fertilization and leaf concentration of defense compounds. However, the picture seems more complicated (Fagard et al. 2014). Although nitrogen starvation has been shown to increase rice susceptibility by reducing cell wall thickness and lignification (Matsuyama 1975; Matsuyama and Dimond 1973), it has also been shown to increase the concentration of leaf phenolic compounds and to lower the level of epidemics in wheat (Király 1964). These contrasted empirical data support the hypothesis formulated by ecologists of a trade-off between plant growth and defense (Herms and Mattson 1992; Walters and Heil 2007). Including such trade-off in our theoretical framework is possible and would add biological realism. To do so, one possibility is to perform the analyses simulating more aggressive strains or more resistant plants dependent on fertilization level by changing the resource conversion coefficients of the pathogen (Table $1, c_{M}$ and $c_{S}$ ) or its maximal uptake rate $\left(I_{\max }\right)$. This could test the hypothesis of Hoffland et al. (2000), which suggested that susceptibility of

TABLE 1. Biological model parameters and their default values, representing the wheat-brown rust pathosystem

\begin{tabular}{|c|c|c|c|}
\hline Symbol & Value & Unit $^{\mathrm{a}}$ & Interpretation \\
\hline$T_{\text {season }}$ & 2,500 & dd & End of season \\
\hline$T_{\text {grow }}$ & 1,500 & dd & End of period of canopy growth \\
\hline$T_{\text {inoc }}$ & 1,000 & dd & $\begin{array}{l}\text { Date of primary inoculation (annual } \\
\text { start date of epidemic) }\end{array}$ \\
\hline$K$ & $0.1-2$ & $\mathrm{~g}$ & Within-patch resource carrying capacity \\
\hline$\pi_{0}$ & 0.3 & $\mathrm{dd}^{-1}$ & Intrinsic rate of photosynthesis \\
\hline$\tau$ & $400-1,300$ & dd & $\begin{array}{l}\text { Maximum patch age for photosynthesis } \\
\text { (patch lifespan) }\end{array}$ \\
\hline$\Psi$ & 0.02 & $\mathrm{dd}^{-1}$ & $\begin{array}{l}\text { Export rate of resource from patch to } \\
\text { common pool }\end{array}$ \\
\hline$R_{0}$ & 0.03 & $\mathrm{~g}$ & Initial resource level at patch creation \\
\hline$M_{0}$ & 0.0001 & $\mathrm{~g}$ & $\begin{array}{l}\text { Initial mycelium biomass at patch } \\
\text { infection }\end{array}$ \\
\hline$R_{\min }$ & 0.02 & $\mathrm{~g}$ & $\begin{array}{l}\text { Minimum resource level for patch } \\
\text { survival }\end{array}$ \\
\hline$I_{\max }$ & 0.06 & $\underset{\mathrm{dd}^{-1}}{\mathrm{~g}}$ & $\begin{array}{l}\text { Maximum resource uptake rate per unit } \\
\text { of mycelium biomass }\end{array}$ \\
\hline$R_{H}$ & 0.25 & $\mathrm{~g}$ & $\begin{array}{l}\text { Half-saturation coefficient for } \\
\text { functional response of resource uptake }\end{array}$ \\
\hline$c_{M}$ & 0.2 & $\ldots$ & $\begin{array}{l}\text { Conversion coefficient for resource- } \\
\text { mycelium conversion }\end{array}$ \\
\hline$c_{S}$ & 0.2 & $\ldots$ & $\begin{array}{l}\text { Conversion coefficient for resource- } \\
\text { spores conversion }\end{array}$ \\
\hline$c_{L T R}$ & 50 & $\mathrm{~g}^{-1}$ & Constant for computing LTR \\
\hline$\lambda$ & $10-350$ & $\mathrm{dd}$ & Latent period \\
\hline$\gamma_{M}$ & 0.001 & $\mathrm{dd}^{-1}$ & Mycelium decay rate \\
\hline$\gamma_{S}$ & 0.001 & $\mathrm{dd}^{-1}$ & Spores decay rate \\
\hline$A_{H}$ & 100 & $\mathrm{~g}$ & $\begin{array}{l}\text { Half-saturation coefficient of pool } \\
\text { resource level for patch creation }\end{array}$ \\
\hline$\rho$ & $0.1-2$ & $\mathrm{dd}^{-1}$ & Maximum rate of patch creation \\
\hline$c_{A}$ & 1 & $\underset{\mathrm{dd}^{-1}}{\mathrm{~g}}$ & Cost of patch creation \\
\hline$\beta$ & 100 & $\mathrm{dd}^{-1}$ & Dispersal efficiency \\
\hline$\Delta$ & 250 & dd & Maximum dispersal distance \\
\hline$\omega$ & 0.1 & $\ldots$ & $\begin{array}{l}\text { Spore survival probability over the } \\
\text { unfavorable season }\end{array}$ \\
\hline$a_{\text {inoc, } \min }$ & 20 & dd & $\begin{array}{l}\text { Minimum patch age to receive primary } \\
\text { inoculum }\end{array}$ \\
\hline$a_{\text {inoc, } \max }$ & 250 & dd & $\begin{array}{l}\text { Maximum patch age to receive primary } \\
\text { inoculum }\end{array}$ \\
\hline$\theta_{\max }$ & 0.02 & $\ldots$ & $\begin{array}{l}\text { Maximum fraction of patches per cohort } \\
\text { that can be inoculated }\end{array}$ \\
\hline$P_{H}$ & 10 & $\mathrm{~g}$ & $\begin{array}{l}\text { Half-saturation coefficient of spore } \\
\text { biomass for spores-limited inoculation }\end{array}$ \\
\hline
\end{tabular}

a Symbol: dd = degree-days. 
disease is the result of the source of nutrients available to the pathogens and the presence of secondary host metabolites.

In our study, we considered a susceptible cultivar. An interesting perspective would be to test how pathogens would behave with more resistant cultivars under varied fertilization. Performing similar analyses but changing the infection cycle parameters would give us an insight into possible interactions between host resistance and fertilization. In our model, we assumed that all patches were equally susceptible to infection by the pathogen. However, in the field, leaf susceptibility may decrease with leaf age and increase with leaf rank on the main stem (Farber and Mundt 2017). The existence of two separate scales in our model, the patch scale and the canopy scale, would make it easy to take such time-dependent susceptibilities into account.

Fungal crop epidemics are dependent on climatic and weather conditions. For instance, under a warmer climate, leaf rust epidemics start earlier in the spring and even in the fall (Duvivier et al. 2016; El Jarroudi et al. 2014). The current parametrization of our model simulates epidemics starting in approximately late April (for northern France, approximately 1,000 dd postsowing, in general), with a fungus that does not significantly hamper plant architecture (Fig. 4, patch creation). This resembles "average" epidemics currently occurring in northwestern Europe. Although our model does not allow us to explicitly change weather and climatic conditions, we can simulate more favorable climatic scenarios by advancing the starting date of the infection parameter or the infection strength of patches.

Thus far, few studies have addressed the question of optimal resource allocation strategy of filamentous fungi. Using a modeling approach on saprophytic fungi, Gilchrist et al. (2006) found that the optimal strategy for these organisms was to allocate $100 \%$ of the resources first into growth (during the latent period) and then into reproduction. That strategy, which we use in our model, is common among holometabolous insects and annual plants growing in a "constant" environment (Cohen 1971, 1976). It has been named the bang-bang strategy by Vincent and Pulliam (1980). In contrast, rust lesions on wheat leaves do not stop growing after the first uredia have broken through the epidermis. Lesions continue to spread laterally during the whole infectious period. We intend to relax this hypothesis in future versions of our model by allowing the mycelium to continue to receive a fraction of the derived resources during the sporulating period using an alternative rule for energy allocation.

We studied two versions of the model, with lesion maturation at either a fixed age or a fixed size. Thus, maturity occurred at a given age or a given size. In the second version of the model, the latent period was a variable that changed with resource level. Interestingly, we observed that the latent period at the optimal size at maturation was nearly identical to the optimal latent period in the first model. In brief, assuming either a fixed age at maturation or a fixed size at maturation does not change our results.

Conclusion. Our modeling results suggest that effects of fertilization on within-leaf resource level, leaf lifespan, and canopy size all contribute to worsening biotrophic fungal epidemics in high fertilization by increasing the level of resources available to the pathogen. Depending on what fitness measure we use, we got contrasting results regarding the relationship of the optimal latent period to fertilization. We predict that high resource levels would allow more strains with different latent periods to coexist in the field than low resource levels. Because the optimal latent period changes with resource level, we expect that reducing fertilization will change the aggressiveness profiles of different biotrophic pathogen species or strains in the field. In the future, it would be interesting to generalize our results to other types of crop pathogens such as necrotrophs or hemibiotrophs.

\section{ACKNOWLEDGMENTS}

P.-A. Précigout received funding from the Institut National de la Recherche Agronomique in the form of a Contrat Jeunes Scientifiques grant. D. Claessen and C. Robert were supported through the Projet Incitatif grant from Ecole Normale Supérieure called "Towards an agro-ecological theory of plant-pathogen interactions". We thank M. Maillard and M. Gélin for their contribution to the modelling work and C. Gigot for his advice during the redaction process.

\section{LITERATURE CITED}

Abro, M. A., Lecompte, F., Bryone, F., and Nicot, P. C. 2013. Nitrogen fertilization of the host plant influences production and pathogenicity of $\mathrm{Bo}$ trytis cinerea secondary inoculum. Phytopathology 103:261-267.

Agrios, G. N. 2005. Plant diseases caused by fungi. Pages 562-582 in: Plant Pathology, 5th ed. Academic Press, Cambridge, MA.

Alexander, H. M., Groth, J. V., and Roelfs, A. P. 1985. Virulence changes in Uromyces appendiculatus after fixed asexual generations on a partially resistant cultivar of Phaseolus vulgaris. Phytopathology 75:449-453.

Aust, H., and Hoyningen-Huene, J. V. 1986. Microclimate in relation to epidemics of powdery mildew. Annu. Rev. Phytopathol. 24:491-510.

Bainbridge, A. 1974. Effect of nitrogen nutrition of the host on barley powdery mildew. Plant Pathol. 23:160-161.

Bernard, F., Sache, I., Suffert, F., and Chelle, M. 2013. The development of a foliar fungal pathogen does react to leaf temperature! New Phytol. 198:232-240.

Biffen, R. H. 1905. Mendel's laws of inheritance and wheat breeding. J. Agric. Sci. 1:4-48.

Calonnec, A., Burie, J.-B., Langlais, M., Guyader, S., Saint-Jean, S. Sache, I., and Tivoli, B. 2013. Impacts of plant growth and architecture on pathogen processes and their consequences for epidemic behaviour. Eur. J. Plant Pathol. 135:479-497.

Cohen, D. 1971. Maximizing final yield when growth is limited by time or by limiting resources. J. Theor. Biol. 33:299-307.

Cohen, D. 1976. On the optimal timing of reproduction. Am. Nat. 110:801-807.

Daamen, R. A., Wijnands, F. G., and van der Vliet, G. 1989. Epidemics of diseases and pests of winter wheat at different levels of agrochemical input. J. Phytopathol. 125:305-319.

de Roos, A. M. 1997. A gentle introduction to physiologically structured population models. Pages 119-204 in: Structured-Population Models in Marine, Terrestrial, and Freshwater Systems. Population and Community Biology Series, Vol. 18. S. Tuljapurkar and H. Caswell, eds. Springer, Berlin, Germany.

de Roos, A. M. 2014. EBTtool: Escalator Boxcar Train tool. Online publication. Institute for Biodiversity and Ecosystem Dynamics. https://staff. fnwi.uva.nl/a.m.deroos/EBT/

de Roos, A. M., and Persson, L. 2013. Population and Community Ecology of Ontogenetic Development. Monographs in Population Biology 51. Princeton University Press, Princeton, NJ.

Dordas, C. 2008. Role of nutrients in controlling plant diseases in sustainable agriculture. A review. Agron. Sustain. Dev. 28:33-46.

Duvivier, M., Dedeurwaerder, G., Bataille, C., De Proft, M., and Legrève, A. 2016. Real-time PCR quantification and spatio-temporal distribution of airborne inoculum of Puccinia triticina in Belgium. Eur. J. Plant Pathol. 145:405-420.

El Jarroudi, M., Kouadio, L., Delfosse, P., and Tychon, B. 2014. Brown rust disease control in winter wheat: I. Exploring an approach for disease progression based on night weather conditions. Environ. Sci. Pollut. Res. 21:4797-4808.

Engen, S., and Saether, B. 1994. Optimal allocation of resources to growth and reproduction. Theor. Popul. Biol. 46:232-248.

English, J. T., Thomas, C. S., Marois, J. J., and Gubler, W. D. 1989. Microclimates of grapevine canopies associated with leaf removal and control of Botrytis bunch rot. Phytopathology 79:395-401.

Fagard, M., Launay, A., Clément, G., Courtial, J., Dellagi, A., Farjad, M., Krapp, A., Soulié, M.-C., and Masclaux-Daubresse, C. 2014. Nitrogen metabolism meets phytopathology. J. Exp. Bot. 65:5643-5656.

Farber, D., and Mundt, C. 2017. Effect of plant age and leaf position on susceptibility to wheat stripe rust. Phytopathology 107:412-417.

Ferrise, R., Triossi, A., Stratonovitch, P., Bindi, M., and Martre, P. 2010. Sowing date and nitrogen fertilisation effects on dry matter and nitrogen dynamics for durum wheat: An experimental and simulation study. Field Crops Res. 117:245-257.

Filella, I., Serrano, L., Serra, J., and Penuelas, J. 1995. Evaluating wheat nitrogen status with canopy reflectance indices and discriminant analysis. Crop Sci. 35:1400-1405.

Fraaije, B. A., Lovell, D. J., Coelho, J. M., Baldwin, S., and Hollomon, D. W. 2001. PCR-based assays to assess wheat varietal resistance to blotch (Septoria tritici and Stagonospora nodorum) and rust (Puccinia striiformis and Puccinia recondita) diseases. Eur. J. Plant Pathol. 107:905-917.

Frezal, L., Robert, C., Bancal, M.-O., and Lannou, C. 2009. Local dispersal of Puccinia triticina and wheat canopy structure. Phytopathology 99:1216-1224.

Garin, G., Fournier, C., Andrieu, B., Houlès, V., Robert, C., and Pradal, C. 2014. A modelling framework to simulate foliar fungal epidemics using functional-structural plant models. Ann. Bot. 114:795-812. 
Garnica, D. P., Nemri, A., Upadhyaya, N. M., Rathjen, J. P., and Dodds, P. N. 2014. The ins and outs of rust haustoria. PLoS Pathog. 10:e1004329.

Gigot, C., De Vallavieille-Pope, C., Huber, L., and Saint-Jean, S. 2014. Using virtual 3-D plant architecture to assess fungal pathogen splash dispersal in heterogeneous canopies: A case study with cultivar mixtures and a nonspecialized disease causal agent. Ann. Bot. 114:863-876.

Gilchrist, M. A., Sulsky, D. L., and Pringle, A. 2006. Identifying fitness and optimal life-history strategies for an asexual filamentous fungus. Evolution 60:970-979.

Greenhalgh, D. 1997. Hopf bifurcation in epidemic models with a latent period and nonpermanent immunity. Math. Comput. Model. 25:85-107.

Grover, J. P. 1997. Resource Competition. Population and Community Biology Series, Vol. 19. Springer Science \& Business Media, Chapman \& Hall, New York.

Haueisen, J., and Stukenbrock, E. H. 2016. Life cycle specialization of filamentous pathogens - colonization and reproduction in plant tissues. Curr. Opin. Microbiol. 32:31-37.

Heesterbeek, J. A. P. 2002. A brief history of R0 and a recipe for its calculation. Acta Biotheor. 50:189-204.

Heraudet, V., Salvaudon, L., and Shykoff, J. A. 2008. Trade-off between latent period and transmission success of a plant pathogen revealed by phenotypic correlations. Evol. Ecol. Res. 10:913-924.

Herms, D. A., and Mattson, W. J. 1992. The dilemma of plants: To grow or defend. Q. Rev. Biol. 67:283-335.

Hinzman, L. D., Bauer, M. E., and Daughtry, C. S. T. 1986. Effects of nitrogen fertilization on growth and reflectance characteristics of winter wheat. Remote Sens. Environ. 19:47-61.

Hoffland, E., Jeger, M. J., and van Beusichem, M. L. 2000. Effect of nitrogen supply rate on disease resistance in tomato depends on the pathogen. Plant Soil 218:239-247.

Jensen, B. 1995. Nitrogen induced changes in the development of barley powdery mildew (Erysiphe graminis f. sp. hordei). Ph.D. thesis, The Royal Veterinary and Agricultural University, Copenhagen.

Jensen, B., and Munk, L. 1997. Nitrogen-induced changes in colony density and spore production of Erysiphe graminis f. sp. hordei on seedlings of six spring barley cultivars. Plant Pathol. 46:191-202.

Kilpatrick, R. A. 1975. New Wheat Cultivars and Longevity of Rust Resistance, 1971-75. Agric. Res. Serv. NE-64. United States Department of Agriculture, Beltsville, MD

Király, Z. 1964. Effect of nitrogen fertilization on phenol metabolism and stem rust susceptibility of wheat. J. Phytopathol. 51:252-261.

Kozłowski, J. 1992. Optimal allocation of resources to growth and reproduction: Implications for age and size at maturity. Trends Ecol. Evol. 7:15-19.

Kürschner, E., Bonman, J., Garrity, D. P., Tamisin, M. M., Pabale, D., and Estrada, B. A. 1992. Effects of nitrogen timing and split application on blast disease in upland rice. Plant Dis. 76:384-389.

Lecompte, F., Abro, M. A., and Nicot, P. C. 2010. Contrasted responses of Botrytis cinerea isolates developing on tomato plants grown under different nitrogen nutrition regimes. Plant Pathol. 59:891-899.

Lehman, J. S., and Shaner, G. 1997. Selection of populations of Puccinia recondita $\mathrm{f}$. sp. tritici for shortened latent period on a partially resistant wheat cultivar. Phytopathology 87:170-176.

Lemmens, M., Buerstmayr, H., Krska, R., Schuhmacher, R., Grausgruber, H., and Ruckenbauer, P. 2004. The effect of inoculation treatment and long-term application of moisture on Fusarium head blight symptoms and deoxynivalenol contamination in wheat grains. Eur. J. Plant Pathol. 110:299-308.

Li, M. Y., and Muldowney, J. S. 1995. Global stability for the SEIR model in epidemiology. Math. Biosci. 125:155-164.

Loreau, M. 1998. Biodiversity and ecosystem functioning: A mechanistic model. Proc. Natl. Acad. Sci. USA 95:5632-5636.

Lovell, D. J., Hunter, T., Powers, S. J., Parker, S. R., and Van Den Bosch, F. 2004. Effect of temperature on latent period of Septoria leaf blotch on winter wheat under outdoor conditions. Plant Pathol. 53:170-181.

Lovell, D. J., Parker, S. R., Hunter, T., Royle, D. J., and Coker, R. R. 1997. Influence of crop growth and structure on the risk of epidemics by Mycosphaerella graminicola (Septoria tritici) in winter wheat. Plant Pathol. 46:126-138.

Matsuyama, N. 1975. The effect of ample nitrogen fertilizer on cell-wall materials and its significance to rice blast disease. Jpn. J. Phytopathol. 41:56-61.

Matsuyama, N., and Dimond, A. E. 1973. Effect of nitrogenous fertilizer on biochemical processes that could affect lesion size of rice blast. Phytopathology 63:1202-1203.

McDonald, B. A., and Linde, C. 2002. Pathogen population genetics, evolutionary potential, and durable resistance. Annu. Rev. Phytopathol. 40: 349-379.

McIntosh, R. A., and Brown, G. N. 1997. Anticipatory breeding for resistance to rust diseases in wheat. Annu. Rev. Phytopathol. 35:311-326.

Mendgen, K., and Hahn, M. 2002. Plant infection and the establishment of fungal biotrophy. Trends Plant Sci. 7:352-356.

Montarry, J., Cartolaro, P., Delmotte, F., Jolivet, J., and Willocquet, L. 2008. Genetic structure and aggressiveness of Erysiphe necator populations during grapevine powdery mildew epidemics. Appl. Environ. Microbiol. 74: 6327-6332.

Naseri, R., Mirzaei, A., Soleimani, R., and Nazarbeygi, E. 2010. Response of bread wheat to nitrogen application in calcareous soils of western Iran. Am.-Eurasian J. Agric. Environ. Sci. 9:79-85.

Neumann, S., Paveley, N. D., Beed, F. D., and Sylvester-Bradley, R. 2004. Nitrogen per unit leaf area affects the upper asymptote of Puccinia striiformis f. sp. tritici epidemics in winter wheat. Plant Pathol. 53: 725-732.

Olesen, J. E., Jørgensen, L. N., Petersen, J., and Mortensen, J. V. 2003a. Effects of rate and timing of nitrogen fertilizer on disease control by fungicides in winter wheat. 1. Grain yield and foliar disease control. J. Agric. Sci. 140:1-13.

Olesen, J. E., Jørgensen, L. N., Petersen, J., and Mortensen, J. V. 2003b. Effects of rates and timing of nitrogen fertilizer on disease control by fungicides in winter wheat. 2. Crop growth and disease development. J. Agric. Sci. 140:15-29.

Pariaud, B., Van den Berg, F., Van den Bosch, F., Powers, S. J., Kaltz, O., and Lannou, C. 2013. Shared influence of pathogen and host genetics on a trade-off between latent period and spore production capacity in the wheat pathogen, Puccinia triticina. Evol. Appl. 6:303-312.

Parlevliet, J. E. 1979. Components of resistance that reduce the rate of epidemic development. Annu. Rev. Phytopathol. 17:203-222.

Pringle, A., and Taylor, J. W. 2002. The fitness of filamentous fungi. Trends Microbiol. 10:474-481.

Robert, C., Bancal, M.-O., and Lannou, C. 2002. Wheat leaf rust uredospore production and carbon and nitrogen export in relation to lesion size and density. Phytopathology 92:762-8.

Robert, C., Bancal, M.-O., and Lannou, C. 2004. Wheat leaf rust uredospore production on adult plants: Influence of leaf nitrogen content and Septoria tritici blotch. Phytopathology 94:712-21.

Robert, C., Bancal, M. O., Lannou, C., and Ney, B. 2006. Quantification of the effects of Septoria tritici blotch on wheat leaf gas exchange with respect to lesion age, leaf number, and leaf nitrogen status. J. Exp. Bot. 57: 225-234.

Robert, C., Bancal, M.-O., Ney, B., and Lannou, C. 2005. Wheat leaf photosynthesis loss due to leaf rust, with respect to lesion development and leaf nitrogen status. New Phytol. 165:227-241.

Robert, C., Fournier, C., Andrieu, B., and Ney, B. 2008. Coupling a 3D virtual wheat (Triticum aestivum) plant model with a Septoria tritici epidemic model (Septo3D): A new approach to investigate plant-pathogen interactions linked to canopy architecture. Funct. Plant Biol. 35:997-1013.

Roff, D. A. 2002. Life History Evolution. Sinauer Associates, Sunderland, MA.

Roumen, E. C., and de Boef, W. S. 1993. Latent period to leaf blast in rice and its importance as a component of partial resistance. Euphytica 69: 185-190.

Saint-Jean, S., Chelle, M., and Huber, L. 2004. Modelling water transfer by rain-splash in a 3D canopy using Monte Carlo integration. Agric. For. Meteorol. 121:183-196.

Savary, S., Castilla, N., and Elazegui, F. 1995. Direct and indirect effects of nitrogen supply and disease source structure on rice sheath blight spread. Phytopathology 85:959-965.

Setti, B., Bencheikh, M., Henni, J., and Neema, C. 2009. Comparative aggressiveness of Mycosphaerella pinodes on peas from different regions in western Algeria. Phytopathol. Mediterr. 48:195-204.

Shaner, G., and Finney, R. E. 1980. New sources of slow leaf rusting resistance in wheat. Phytopathology 70:1183-1186.

Smith, H. C., and Blair, I. D. 1950. Wheat powdery mildew investigations. Ann. Appl. Biol. 37:570-583.

Suffert, F., Ravigné, V., and Sachec, I. 2015. Seasonal changes drive shortterm selection for fitness traits in the wheat pathogen Zymoseptoria tritici. Appl. Environ. Microbiol. 81:6367-6379.

Tilman, D., Reich, P. B., Knops, J., Wedin, D., Mielke, T., and Lehman, C. 2001. Diversity and productivity in a long-term grassland experiment. Science 294:843-845.

Van Den Berg, F., Robert, C., Shaw, M. W., and Van Den Bosch, F. 2007. Apical leaf necrosis and leaf nitrogen dynamics in diseased leaves: A model study. Plant Pathol. 56:424-436.

Vincent, T. L., and Pulliam, H. R. 1980. Evolution of life history strategies for an asexual annual plant model. Theor. Popul. Biol. 17:215-231.

Walters, D., and Heil, M. 2007. Costs and trade-offs associated with induced resistance. Physiol. Mol. Plant Pathol. 71:3-17.

Walters, D. R., and Bingham, I. J. 2007. Influence of nutrition on disease development caused by fungal pathogens: Implications for plant disease control. Ann. Appl. Biol. 151:307-324.

Xue, G., and Hall, R. 1992. Effects of surface wetness duration, temperature, and inoculum concentration on infection of winter barley by Rhynchosporium secalis. Phytoprotection 73:61-68. 